\title{
Cardiovascular evaluation of patients undergoing cancer treatment at a clinic for childhood cancer survivors in Mexico
}

\section{Evaluación cardiovascular de pacientes sometidos a tratamientos oncológicos en una clínica de supervivientes de cáncer infantil en México}

\author{
María G. Jiménez-Carbajal*, Sandra P. Antúnez-Sánchez², Farina E. Arreguín-González³, and \\ Alma E. Benito-Reséndiz ${ }^{4}$ \\ ${ }^{1}$ Department of Cardiology, Centro Médico ABC; ${ }^{2}$ Department of Pediatric Echocardiography; ${ }^{3}$ Department of Pediatric Oncology; ${ }^{4}$ Childhood Cancer
} Survivors Clinic. Centro Médico Nacional 20 de Noviembre. Mexico City, Mexico

\begin{abstract}
Objective: The objective of the study was to describe the cardiovascular effects of childhood cancer treatment in survivors through clinical, electrocardiogram, and echocardiographic methods. Materials and methods: Prospective, observational case-control study of 34 patients of a Childhood Cancer Survivors Clinic, evaluated clinically, with electrocardiogram, with conventional echocardiography and strain. Average age 13.03 years; the average cumulative dose of anthracyclics was 219.5 $\mathrm{mg} / \mathrm{m} 2$; seven patients also received chest radiation. The analysis was done with Student's T-tests and linear regression. Results: Left ejection fraction (EF) in survivors was preserved. Longitudinal left strain in two, three chambers, and circumferential was decreased in survivors $(p<0.05)$. Those undergoing radiotherapy and anthracyclic presented increased heart rate, $E F$, left shortening fraction decreased $(<0.05)$, and right ventricle without significant changes. Discussion and conclusions: There are a large number of childhood cancer survivors treated with cardiotoxics and radiotherapy. They may present changes in ventricular myocardial strain (even with normal EF) and/or arrhythmias, as evidenced in the group studied, which is consistent with the previous international studies. Its complete cardiovascular evaluation is important to predict the risk of heart failure as part of a protocolized follow-up in well-established cardio oncology clinics.
\end{abstract}

Key words: Cardiovascular evaluation. Childhood cancer. Survivors. Strain.

\section{Resumen}

Objetivo: Describir los efectos cardiovasculares del tratamiento del cáncer infantil en supervivientes mediante métodos clínicos, electrocardiográficos y ecocardiográficos. Material y métodos: Estudio transversal y observacional de casos y controles de 34 pacientes de una clínica de supervivientes de cáncer infantil, evaluados de forma clínica, con electrocardiograma, ecocardiografía convencional y strain. Edad promedio de 13.03 años; dosis acumulada de antracíclicos promedio de $219.5 \mathrm{mg} / \mathrm{m}^{2}$; siete además con radiación a tórax. Análisis con pruebas T de Student y regresión lineal. Resultados: Fracción de expulsión izquierda preservada en supervivientes. Strain longitudinal izquierdo en dos, tres cámaras y circunferencial

Correspondence:

*María G. Jiménez-Carbajal

E-mail: mgjcmed@yahoo.com.mx
Date of reception: 17-02-2019

Date of acceptance: 23-04-2020

DOI: $10.24875 /$ ACME.M21000173
Available online: $25-05-2021$

Arch Cardiol Mex (Eng). 2021;91(1):24-32 www.archivoscardiologia.com 2604-7063 / @ 2020 Instituto Nacional de Cardiología Ignacio Chávez. Published by Permanyer. This is an open access article under the CC BY-NC-ND license (http://creativecommons.org/licenses/by-nc-nd/4.0/). 
disminuido en supervivientes $(p<0.05)$. Los enfermos sometidos a radioterapia y antracíclicos mostraron un incremento de la frecuencia cardíaca, disminución de la fracción de expulsión y fracción de acortamiento izquierdos $(<0.05)$. Ventrículo derecho sin cambios significativos. Discusión y conclusiones: Existe un gran número de supervivientes de cáncer infantil tratados con cardiotóxicos y radioterapia; éstos pueden experimentar cambios en el strain miocárdico ventricular (aun con fracción de expulsión normal) o arritmias, como lo muestra el grupo estudiado, que concuerda con protocolos internacionales previos. Es importante su evaluación cardiovascular completa para predecir el riesgo de insuficiencia cardíaca como parte de un seguimiento protocolizado en clínicas de cardiooncología bien establecidas.

Palabras clave: Evaluación cardiovascular. Cáncer infantil. Supervivientes. Strain.

\section{Introduction}

At present, the rate of cure of children with hemato-oncological conditions is estimated to be higher than $80 \%$, which increases the expectation of disease-free survival, but also the likelihood of multi-organ toxicity, including cardiac toxicity, in association with different treatments. This creates the need to early detect and treat complications to improve patient quality of life $e^{1-3}$. Around $65 \%$ of childhood cancer survivors who were treated with anthracyclines have subclinical myocardial dysfunction ${ }^{4}$. An incidence of clinical heart failure as high as $16 \%$ has been reported 0.9-4.8 years after chemotherapy ${ }^{1,5}$. Among childhood cancer survivors, cardiovascular disease is the leading cause of morbidity and mortality due to cardiotoxicity, after cancer recurrence and secondary neoplasms $\mathbf{s}^{1,6,7}$.

Cardiotoxicity is the series of cardiovascular disorders deriving from hemato-oncological treatments ${ }^{8}$. Cardiotoxicity can be defined based on left ventricular ejection fraction (LVEF) deterioration ${ }^{9,10}$ :

Grade I: $10-20 \%$ ejection fraction $(E F)$ reduction with regard to baseline.

Grade II: higher than $20 \%$ reduction or decrease below normal $(p<55 \%)$.

Grade III: congestive heart failure symptoms onset.

The American Society of Echocardiography and the European Association of Cardiovascular Imaging use $53 \%$ as normal limit ${ }^{8,11}$.

In addition, there are toxic effects that can be expressed through the onset of acute coronary syndrome, hypertension, thromboembolic phenomena, pericardial disease, valvular disease, arrhythmias, and QT-interval alterations ${ }^{12}$.

According to the time variable, cardiotoxicity may occur early during treatment and up to 40 years after its conclusion ${ }^{13,14}$. Among antineoplastic agents, the drugs that entail the risk of producing cardiotoxicity are classified in two types ${ }^{13}$ : I, cardiotoxicity with anthracycline-like mechanism, whose cardiac toxicity is dose-dependent and causes irreversible heart damage ${ }^{13}$; II, cardiotoxicity with trastuzumab-like mechanism, related to a reversible heart damage and that allows functionality recovery and restarting the regimen if indicated ${ }^{13}$; these drugs act by binding to HER2 extracellular domain, which they internalize ${ }^{13}$.

Better results have been shown in the treatment of patients with oncological conditions with the combined prescription of chemotherapy and radiotherapy; however, similar to chemotherapeutic drugs, radiation therapy can induce secondary cardiotoxic effects, such as myocardial fibrosis, cardiomyopathy, early coronary artery disease and valvular and electrophysiological dysfunction. This cardiotoxicity is the effect of acute damage and inflammation that lead to long-term myocardial fibrosis. The risk of these side effects increases 2- 6 times in patients receiving chest radiation at high doses. Radiation cardiotoxicity also is dose-dependent and is correlated with the exposed area of the heart and the radiological technique employed, as well as patient age, with a higher incidence in younger individuals. Individuals receiving more than 1500-3500 cGy show a higher risk of heart disease; high doses are related to myocardial ischemia 12 years after treatment and thereafter ${ }^{15-18}$.

All patients treated with potentially cardiotoxic cancer drugs should undergo a thorough clinical evaluation to determine the presence of a history of cardiovascular conditions and to cardiovascular assessment. On clinical examination, the presence of signs of heart failure should be identified. Vital signs frequent monitoring during chemotherapeutic agents infusion is recommended ${ }^{9}$.

An electrocardiogram is also recommended in all subjects before and during treatment to identify any electrocardiographic signs of cardiac toxicity, including tachycardia at rest, changes in the ST-T wave, conduction disorders, QT-interval prolongation, or arrhythmias ${ }^{19}$.

Although LVEF is the parameter regularly used to make decisions, it is not sensitive for subclinical cardiac compromise early detection and is influenced by preload and afterload changes, which lead to transitory changes in it. Strain and strain rate determination have 
emerged as promising techniques and could play a major role in ventricular dysfunction early detection $^{9,20,21}$. At baseline, global longitudinal strain (GLS) improves cardiotoxicity-associated ventricular dysfunction risk stratification with regard to 2D-LVEF. The combined use of GLS and troponin I improves the negative predictive value for ventricular dysfunction ${ }^{8,11}$.

The purpose of this study was to describe, by means of clinical assessment and echocardiography, the side effects exerted by cancer treatment on the cardiovascular system in pediatric-age cancer survivors who underwent oncological treatments, and who were affiliated to the Institute of Health and Social Security for State Workers.

\section{Methods}

A cross-sectional, observational, and case-control convenience study was carried out from June to December 2018, in which 34 consecutive patients aged from 4 to 18 years, 20 males and 14 females, who were under the care of the Childhood Cancer Survivors Clinic of a tertiary care hospital in Mexico City were included in the study. All patients were treated with anthracyclines such as doxorubicin, daunorubicin or epirubicin and other non-anthracycline drugs; in addition, one of them was treated with rituximab and seven with radiotherapy to the mediastinum. The types of treated cancer were Hodgkin's lymphoma $(n=6)$, Wilms tumor $(n=5)$, non-Hodgkin lymphoma $(n=4)$, hepatoblastoma $(n=4)$, neuroblastoma $(n=3)$, Burkitt lymphoma of $(n=2)$, Ewing sarcoma $(n=2)$, rhabdomyosarcoma $(n=2)$, osteosarcoma $(n=1)$, ganglioneuroblastoma $(n=1)$, leiomyosarcoma $(n=1)$, primitive neuroectodermal tumor $(n=1)$, and liver sarcoma $(n=1)$ and one case of acute lymphoblastic leukemia whose treatment was implemented in another health establishment. Mean follow-up time after diagnosis was $7.35 \pm 3.58$ years and mean surveillance time was $5.83 \pm 3.47$ years.

Thirty-one healthy controls were included (20 males and 11 females), systematically referred for echocardiographic evaluation for heart murmur or for detection purposes, as well as healthy patients invited to carry out an inclusion study in the control group. Matching this group with the cohort by age and gender was tried.

Patients who in addition to anthracyclines received radiation to the mediastinum ( $n=7$, who were part of the group of 34 patients) were analyzed and matched with a group of healthy controls $(n=7)$.

The inclusion criteria were defined as follows: patients of pediatric age and up to 18 years old, with diagnosis and treatment (anthracyclines or radiotherapy) of any type of cancer, under the care of the Childhood Cancer Survivors Clinic of a tertiary care hospital of Mexico City, and with informed consent duly completed by the parents or legal guardians of the studied children.

The study was approved by the Ethics and Research Committee of the Hospital. The patients underwent a clinical evaluation that included vital signs taken by the nursing staff, with these variables being measured 10-20 min before the start of the transthoracic echocardiogram, without variables that would alter the measurements being found. Clinical assessment was conducted by the resident physician in charge of the investigation.

Transthoracic echocardiographic examinations were carried out in all 34 study subjects; one patient also underwent transesophageal echocardiogram. Echocardiograms were obtained with ultrasound systems Phillips iE33 xMatrix (QLAB software version 10.7), with 8-3 and 4-2 MHz transducers and Phillips EpiQ 7 (QLAB software, version 11), with 8-3, 5-1, and X5-1 MHz transducers. Patients were placed in supine and left lateral decubitus with four-, three-, and two-chamber subcostal, apical, parasternal long axis, great vessels short axis, mitral valve-level parasternal short axis (basal), papillary muscles-plane (medial) and leftventricular (LV) vertex-level, as well as suprasternal views being obtained; in addition, the study included two-dimensional, M-mode, color, continuous, pulsed, and tissue Doppler modalities with storage of four cardiac cycles of each visualization in cine-loop sequences.

The conventional parameters obtained for the study of the left ventricle, both systolic and diastolic, were acquired according to the criteria established by the American Society of Echocardiography and included EF by Simpson's method in four-chamber plane, fractional shortening (FS), end-diastolic volume (EDV), end-systolic volume (ESV), mitral annular plane systolic excursion (MAPSE), diastolic diameter (DD), systolic diameter (SD), myocardial performance index (TEI index), E/A waves ratio, and E/E' mitral waves ratio.

Right ventricular function conventional echocardiographic parameters included fractional area $(F A)$, tricuspid annular plane systolic excursion (TAPSE), myocardial performance index (TEI index), E/A waves ratio, and E/E' tricuspid waves ratio. Pulmonary artery systolic pressure (PASP) and pulmonary artery mean pressure (PAMP) echocardiographic measurements were carried out using the tricuspid regurgitation (maximum gradient in $\mathrm{mmHg}+$ right atrial pressure calculated according to inferior vena cava collapse) and 
pulmonary insufficiency (early diastolic peak in $\mathrm{mmHg}$ + calculated right atrial pressure according to inferior vena cava collapse) methods.

The strain imaging echocardiographic study was carried out with gray scale and sepia ventricular imaging using the above-described views for both ventricles at a speed 60-90 frames/s, with four cycles being recorded. The analysis was carried out with the same ultrasound system at post-process.

Four operators conducted the studies in a random manner, and two operators in charge of the hospital Pediatric Echocardiography Department validated them. Statistical analysis was performed with the GraphPad Prism 8.0 software, San Diego, Cal., USA for Mac. Continuous variables were expressed using dispersion measures such as the mean \pm standard deviation. Variables normal distribution was observed (Shapiro-Wilk test). Differences between groups were analyzed using the parametric t-test for independent samples. $<0.05$ was considered to statistically significant (calculated by $\mathbf{Z}$ distribution). Linear correlation was used to analyze the correlations between global longitudinal and circumferential strain percentages and cumulative anthracycline doses.

GLS measurement inter-observer agreement was evaluated in the group of cases (performing intra-observer variability assessment was not possible owing to the time assigned to the study), in comparison with the results of both physicians in charge of the Pediatric Echocardiography Department where the study was conducted. The images were obtained according to the above description. The result was expressed as the Kappa coefficient.

\section{Results}

Clinical and demographic characteristics of the study population and controls are summarized in table 1. Anthracycline mean cumulative dose was $219.5 \pm 160.7$ $\mathrm{mg} / \mathrm{m}^{2}$; in 24 of the 34 patients $(70.5 \%)$, a cardioprotective drug was used during anthracycline administration (dexrazoxane). Radiation to the mediastinum cumulative dose was $23 \pm 5.4$ Gy.

As for the surface electrocardiogram, all evaluated patients were in sinus rhythm, two with sinus arrhythmia, three with sinus tachycardia (one of whom also suffered first-degree atrioventricularblock and had a history of Hodgkin's lymphoma, treatment with anthracyclines and radiation therapy to the neck and mediastinum), one with 447-ms corrected QT (Bazett), 17 had incomplete right bundle branch block, and one had atrial and supraventricular extrasystoles.
Table 1. Clinical and demographic characteristics of the study population

\begin{tabular}{|c|c|c|c|}
\hline Variables & $\begin{array}{c}\text { Survivors } \\
(\mathrm{n}=34)\end{array}$ & $\begin{array}{c}\text { Control } \\
\text { group } \\
(n=31)\end{array}$ & p-value \\
\hline Age (years) & $13.03( \pm 4.09)$ & $9.67( \pm 4.33)$ & 0.02106 \\
\hline Gender & $20 \mathrm{H} / 14 \mathrm{M}$ & $20 \mathrm{H} / 11 \mathrm{M}$ & 0.8075 \\
\hline $\mathrm{BSA}\left(\mathrm{m}^{2}\right)$ & $1.38( \pm 0.34)$ & $1.09( \pm 0.39)$ & 0.00227 \\
\hline HR (bpm) & $82.12( \pm 16.43)$ & $79.42( \pm 14.7)$ & 0.489564 \\
\hline SBP $(\mathrm{mmHg})$ & $100.4( \pm 12.57)$ & $95.35( \pm 9.32)$ & 0.075707 \\
\hline $\mathrm{DBP}(\mathrm{mmHg})$ & $61.65( \pm 8.39)$ & $57.32( \pm 8.02)$ & 0.038078 \\
\hline FUTAD (years) & $7.35( \pm 3.58)$ & & \\
\hline SURT (years) & $5.83( \pm 3.47)$ & & \\
\hline ANTCD $(\mathrm{mg} / \mathrm{m} 2)$ & $219.5( \pm 160.7)$ & & \\
\hline $\begin{array}{l}\text { Use of cardioprotective } \\
\text { drugs }\end{array}$ & 24 & & \\
\hline CRTU (no. of patients) & 7 & & \\
\hline RXCD (Gy) & $23( \pm 5.4)$ & & \\
\hline $\begin{array}{l}\text { Oncological diagnoses } \\
\text { (no. of patients,\%) } \\
\text { Hodgkin's lymphoma) } \\
\text { Wilms tumor } \\
\text { Non-Hodgkin } \\
\text { lymphoma } \\
\text { Hepatoblastoma } \\
\text { Neuroblastoma } \\
\text { Burkitt lymphoma } \\
\text { Ewing sarcoma } \\
\text { Rhabdomyosarcoma } \\
\text { Other }\end{array}$ & $\begin{array}{c}6(17.6 \%) \\
5(14.7 \%) \\
4(11.8 \%) \\
\\
4(11.8 \%) \\
3(8.8 \%) \\
2(5.9 \%) \\
2(5.9 \%) \\
2(5.9 \%) \\
6(17.6 \%)\end{array}$ & & \\
\hline
\end{tabular}

BSA: body surface area; HR: heart rate; SBP: systolic blood pressure; DBP: diastolic blood pressure; FUTAD: follow-up time after diagnosis; SURT: surveillance time; ANTCD: anthracycline cumulative dose; CRTU: chest radiation therapy use; RXCD: radiation cumulative dose.

The conventional echocardiographic parameters for LV systolic function that showed a statistically significant difference $(p<0.05)$ with regard to controls were FS, SD, ESV, and EDV (Table 2).

LV function advanced strain imaging study is shown in table 3, where it can be observed that there was no statistically significant difference between global longitudinal and four-chamber values of the study individuals in comparison with the control group, but there were $(p<0.05)$ between two- and three-chamber longitudinal strain, global, basal, medial, and apical circumferential strain values of cancer survivors with regard to controls. Eight of the studied patients registered LV GLS values ranging between $-14.1 \%$ and $-17.9 \%$.

No statistically significant difference was identified between right ventricular conventional and advanced 
Table 2. Conventional echocardiographic parameters in the study of left ventricular function

\begin{tabular}{|l|c|c|c|}
\hline & $\begin{array}{c}\text { Survivors } \\
(\mathbf{n}=34)\end{array}$ & $\begin{array}{c}\text { Control group } \\
(\mathbf{n}=31)\end{array}$ & p-value \\
\hline EF $(\%)$ & $64.49( \pm 5.82)$ & $66.49( \pm 6.33)$ & 0.179218 \\
\hline FS $(\%)$ & $34.59( \pm 5.08)$ & $38.49( \pm 3.74)$ & 0.000884 \\
\hline $\mathrm{DD}(\mathrm{mm})$ & $39.39( \pm 5.5)$ & $36.6( \pm 6.70)$ & 0.071742 \\
\hline EDV $(\mathrm{mL})$ & $55.1( \pm 21)$ & $42.6( \pm 20.6)$ & 0.0168 \\
\hline ESV $(\mathrm{mL})$ & $19.6( \pm 8.3)$ & $14.2( \pm 7.5)$ & 0.0076 \\
\hline $\mathrm{SD}(\mathrm{mm})$ & $25.5( \pm 3.99)$ & $22.7( \pm 3.93)$ & 0.006853 \\
\hline TEl index & $0.33( \pm 0.05)$ & $0.34( \pm 0.04)$ & 0.427662 \\
\hline MAPSE $(\mathrm{mm})$ & $15.04( \pm 3.2)$ & $14.67( \pm 2.23)$ & 0.603457 \\
\hline E/E' ratio & $5.53( \pm 1.34)$ & $5.25( \pm 1.25)$ & 0.38519 \\
\hline
\end{tabular}

EF: ejection fraction; FS: fractional shortening; EDV: end-diastolic volume; ESV: end-systolic volume; DD: diastolic diameter; SD: systolic diameter; TEl index: myocardial performance index; MAPSE: mitral annular plane systolic excursion.

Table 4. Conventional echocardiographic parameters in the study of right ventricular function

\begin{tabular}{|l|c|c|c|}
\hline & $\begin{array}{c}\text { Survivors } \\
(\mathbf{n}=34)\end{array}$ & $\begin{array}{c}\text { Control group } \\
(\mathbf{n}=\mathbf{3 1})\end{array}$ & p-value \\
\hline FA $(\%)$ & $47.9( \pm 8.50)$ & $46.47( \pm 6.62)$ & 0.455659 \\
\hline TEl index & $0.35( \pm 0.06)$ & $0.34( \pm 0.09)$ & 0.5305 \\
\hline TAPSE $(\mathrm{mm})$ & $19.73( \pm 4.6)$ & $18.84( \pm 4.32)$ & 0.428522 \\
\hline E/E' ratio & $4.85( \pm 1.07)$ & $4.55( \pm 1.25)$ & 0.255971 \\
\hline PASP $(\mathrm{mmHg})$ & $26.12( \pm 3.55)$ & $25.84( \pm 1.04)$ & 0.745803 \\
\hline PAMP $(\mathrm{mmHg})$ & $19.53( \pm 2.74)$ & $19.06( \pm 2.25)$ & 0.460464 \\
\hline
\end{tabular}

FA: fractional area; TEl index: myocardial performance index; TAPSE: tricuspid annular plane systolic excursion; PASP: pulmonary artery systolic pressure; PAMP: pulmonary artery mean pressure.

echocardiographic parameters (free wall GLS) of cancer survivors in comparison with the control group (Tables 4 and 5).

Demographic characteristics of the patients undergoing anthracycline treatment and radiation therapy to the mediastinum are shown in table 6 . Therein, a statistically significant difference $(p<0.05)$ in survivors' heart rate with regard to the control group can be observed. It should be noted that, in this group, one patient had a history of ventricular fibrillation during a surgical procedure sometime after cancer treatment, another had echocardiographic findings of frequent atrial and supraventricular extrasystoles, and one more had systemic arterial hypertension, first degree
Table 3. Left ventricular longitudinal and circumferential strain echocardiographic study

\begin{tabular}{|l|c|c|c|}
\hline & $\begin{array}{c}\text { Survivors } \\
(\mathbf{n}=34)\end{array}$ & $\begin{array}{c}\text { Control group } \\
(\mathbf{n}=\mathbf{3 1})\end{array}$ & p-value \\
\hline GLS $(\%)$ & $-21( \pm 4.10)$ & $-22.9( \pm 3.49)$ & 0.071936 \\
\hline 4CLS $(\%)$ & $-22.32( \pm 4.9)$ & $-22.9( \pm 3.82)$ & 0.583876 \\
\hline $3 C L S(\%)$ & $-19.85( \pm 4.5)$ & $-22.9( \pm 3.23)$ & 0.003557 \\
\hline 2 CLS $(\%)$ & $-21.01( \pm 4.52)$ & $-24.14( \pm 5.09)$ & 0.012238 \\
\hline GCS $(\%)$ & $-26.59( \pm 3.52)$ & $-29.56( \pm 4.56)$ & 0.006251 \\
\hline BCS $(\%)$ & $-22.96( \pm 3.65)$ & $-25.57( \pm 6.20)$ & 0.043181 \\
\hline MCS $(\%)$ & $-24.49( \pm 4.35)$ & $-26.96( \pm 4.35)$ & 0.026789 \\
\hline ACS $(\%)$ & $-33.17( \pm 7.24)$ & $-38.08( \pm 8.24)$ & 0.013887 \\
\hline
\end{tabular}

GLS: global longitudinal strain; 4CLS: four-chamber longitudinal strain; 3CLS: three-chamber longitudinal strain; 2CLS: two-chamber longitudinal strain; GCS: global circumferential strain; BCS: basal circumferential strain; MCS: medial circumferential strain; ACS: apical circumferential strain.

Table 5. Right ventricular free wall longitudinal strain echocardiographic study

\begin{tabular}{|l|c|c|c|}
\hline & $\begin{array}{c}\text { Survivors } \\
(\mathbf{n}=34)\end{array}$ & $\begin{array}{c}\text { Control group } \\
(\mathbf{n}=31)\end{array}$ & p-value \\
\hline RVFWBLS $(\%)$ & $-28.78( \pm 9.04)$ & $-30.53( \pm 10.11)$ & 0.502115 \\
\hline RVFWMLS (\%) & $-24.81( \pm 9.15)$ & $-28.58( \pm 9.46)$ & 0.139169 \\
\hline RVFWALS (\%) & $-23.09( \pm 9.31)$ & $-26,97( \pm 7.89)$ & 0.10295 \\
\hline RVFWLS (\%) & $-25.56( \pm 9.16)$ & $-28.69( \pm 8.86)$ & 0.1988 \\
\hline
\end{tabular}

RVFWBLS, right ventricular free wall basal longitudinal strain; RVFWMLS, right ventricular free wall medial longitudinal strain; RVFWALS: right ventricular free wall apical longitudinal strain; RVFWLS: right ventricular free wall longitudinal strain.

atrioventricular block and right ventricular type I diastolic dysfunction.

In the study of conventional echocardiographic parameters, a significant difference was recognized versus controls for LV fractional shortening (Table 7), and in strain there was only difference $(p<0.05)$ with controls in the LV longitudinal strain three-chamber projection.

There was no difference in right ventricular conventional or advanced parameters.

\section{Discussion}

According to large studies, the various treatments pediatric-age patients undergoing cancer treatments are exposed to cause cardiotoxicity; the most studied 
Table 6. Clinical and demographic characteristics of patients treated with anthracyclines + radiotherapy

\begin{tabular}{|c|c|c|c|}
\hline Variables & Survivors $(\mathrm{n}=7)$ & Control group $(n=7)$ & p-value \\
\hline Age (years) & $14.86( \pm 2.96)$ & $14.71( \pm 2.92)$ & 0.978161 \\
\hline Gender & $3 \mathrm{H} / 4 \mathrm{M}$ & $4 \mathrm{H} / 3 \mathrm{M}$ & 0.9999 \\
\hline $\mathrm{BSA}(\mathrm{m} 2)$ & $1.53( \pm 0.32)$ & $1.51( \pm 0.26)$ & 0.894653 \\
\hline HR (bpm) & $93.71( \pm 13.65)$ & $73.86( \pm 14.28)$ & 0.020785 \\
\hline $\mathrm{SBP}(\mathrm{mmHg})$ & $103.7( \pm 18.35)$ & $99.57( \pm 5.88)$ & 0.579903 \\
\hline $\mathrm{DBP}(\mathrm{mmHg})$ & $67.14( \pm 12.54)$ & $60.43( \pm 4.96)$ & 0.212226 \\
\hline FUTAD (years) & $6.71( \pm 1.70)$ & & \\
\hline SURT (years) & $4.57( \pm 1.61)$ & & \\
\hline ANTCD $(\mathrm{mg} / \mathrm{m} 2)$ & $227.5( \pm 97.46)$ & & \\
\hline Use of cardioprotective drugs & 6 & & \\
\hline RXCD (Gy) & $23( \pm 5.4)$ & & \\
\hline $\begin{array}{l}\text { Oncological diagnoses (no. of patients) } \\
\text { Hodgkin's lymphoma) } \\
\text { Wilms tumor }\end{array}$ & $\begin{array}{l}5 \\
2\end{array}$ & & \\
\hline
\end{tabular}

BSA: body surface area; HR: heart rate; SBP: systolic blood pressure; DBP: diastolic blood pressure; FUTAD: follow-up time after diagnosis; SURT: surveillance time; ANTCD: anthracyclines cumulative dose; RXCD: radiation cumulative dose.

Table 7. Conventional echocardiographic parameters in the study of the left ventricular function (patients with anthracycline treatment and radiotherapy)

\begin{tabular}{|l|c|c|c|}
\hline & $\begin{array}{c}\text { Survivors } \\
(\mathbf{n}=7)\end{array}$ & $\begin{array}{c}\text { Control group } \\
(\mathbf{n}=\mathbf{7})\end{array}$ & p-value \\
\hline EF $(\%)$ & $62.97( \pm 2.19)$ & $66.59( \pm 3.37)$ & 0.034906 \\
\hline FS $(\%)$ & $34( \pm 3.39)$ & $38.19( \pm 2.85)$ & 0.02913 \\
\hline $\mathrm{DD}(\mathrm{mm})$ & $38.29( \pm 6.67)$ & $42.9( \pm 3.81)$ & 0.138106 \\
\hline $\mathrm{SD}(\mathrm{mm})$ & $24.7( \pm 4.29)$ & $26.56( \pm 2.72)$ & 0.352906 \\
\hline TEl index & $0.35( \pm 0.07)$ & $0.32( \pm 0.04)$ & 0.382371 \\
\hline MAPSE $(\mathrm{mm})$ & $16.2( \pm 1.67)$ & $16.18( \pm 1.42)$ & 0.985089 \\
\hline E/E' ratio & $5.73( \pm 1.97)$ & $5.16( \pm 0.9)$ & 0.502253 \\
\hline
\end{tabular}

EF: ejection fraction; FS: fractional shortening; DD: diastolic diameter; SD: systolic diameter; TEI index: myocardial performance index; MAPSE: mitral annular plane systolic excursion.

group was that of anthracyclines and trastuzumab-type drugs, as well as radiation to the mediastinum. Our study group has exposure to this type treatments and a surveillance period longer than one decade in some, which increases cardiovascular risk factors as age advances, which adds to known factors, both genetic and environmental, observed in adults. The heart rate figures recorded in patients who, in addition to undergoing treatment with anthracyclines, were treated with radiotherapy to the neck and mediastinum are of interest; in none of the cases were variables identified that would affect its increase, such as pain, fever or irritability, which supports the already-described alterations when combining these two types of treatments for different types of childhood cancer. Only one patient had high blood pressure figures recorded. On the other hand, a decrease in ventricular function advanced parameters was identified, expressed in longitudinal and circumferential myocardial fiber deformation percentage by the strain method, even when in $100 \%$ of the patients, LVEF values obtained by two-dimensional echocardiography were found to be within normal limits, which is a parameter that until recent years was considered the reference standard for LV systolic function detection and monitoring, until evidence on its limitations was published ${ }^{11}$.

As in various international studies, in this study, changes in myocardial fibers deformation were observed to exist in asymptomatic patients with normal conventional echocardiogram. Consequently, it is possible to observe that, in the 2017 study by Çetin et al., ${ }^{22}$ 45 childhood cancer survivors had lower anterior, radial anteroseptal, and radial anterior strain values compared to controls $(p<0.05)$. Global radial and GLS values were lower in comparison with the control group $(p<0.05)$. Both groups had normal EF and fractional 
shortening. Brain natriuretic peptide values were within the normal range.

In the 2015 study by Pignatelli ${ }^{23}$ with a study group of 25 childhood cancer survivors with a mean age of $9.8 \pm 5.8$ years, who received anthracyclines with median cumulative dose of $150 \pm 124.4 \mathrm{mg} / \mathrm{m}^{2}$ and a range of $60-450 \mathrm{mg} / \mathrm{m}^{2}$, normal LV diastolic diameter and EF were identified, but with decreased GLS and global circumferential strain; however, they were poorly correlated with anthracycline cumulative dose, which is similar to that which was observed in this study, where $\mathrm{R} 2$ was found to be far-off the unit in linear regression analyses (Figs. 1 and 2).

The GLS normal ranges defined in the meta-analysis published in 2013 by Yingchoncharoen et al. ${ }^{24}$ approve the use of a cutoff value of normal higher than $-19.7 \%$, and values $<19 \%$ were found for the same parameter in all patients who later developed heart failure. Nevertheless, there is great variability in values in different groups of patients; therefore, comparison with initial values in each subject is considered adequate, and a change $>15 \%$ from baseline value is considered significant ${ }^{8}$.

Studies have been recently published that support LV twist and torsion evaluation as a predictive parameter of early myocardial damage, butfurtherstudies are suggested on the subject for an accurate definition of these parameters ${ }^{25}$.

In this study, LV twist was measured, with a mean of $6.21^{\circ}( \pm 7.26)$ being found in cancer survivors and $7.82^{\circ}$ $( \pm 3.32)$ in the control group, with $p=0.3148$ (non-statistically significant difference). Furthermore, torsion values were also obtained, with a mean of $1.21 \% \mathrm{~cm}$ $( \pm 0.75)$ being found in the cohort and $1.32 \% \mathrm{~cm}( \pm 0.67)$ in the controls, with $p$-value $=0.568609$; even with these numerical calculations, both twist and torsion values were lower in patients exposed to chemotherapy and radiotherapy (Fig. 3).

Although, in this study, assessing LV GLS inter-observer variability was possible only in oncologic patients (not in healthy controls), an intra-class correlation coefficient (R squared) of 0.88 (95\% Confidence Intervals, 0.87-0.97) was recorded, which implies a high reproducibility of the technique employed; detailed study of intra- and inter-observer variability with regard to advanced ventricular function parameters is considered an area of opportunity.

\section{Limitations}

Given the type of study population, some limitations can be pointed out that, according to this experience,

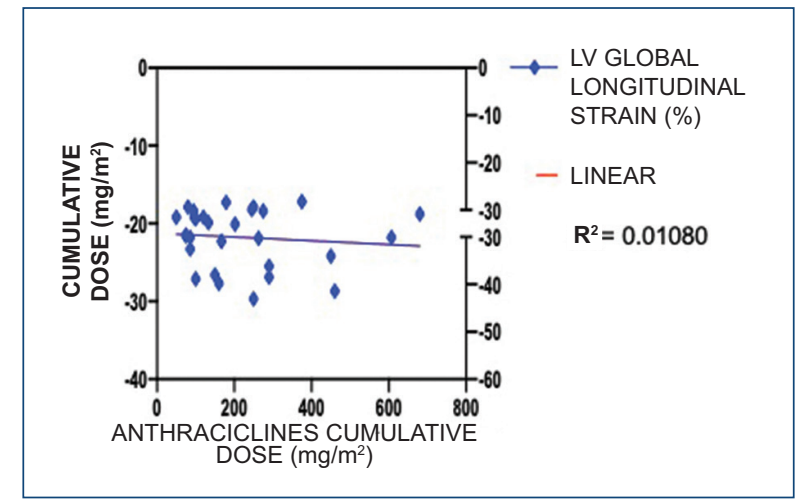

Figure 1. Global longitudinal strain versus anthracyclines cumulative dose linear regression.

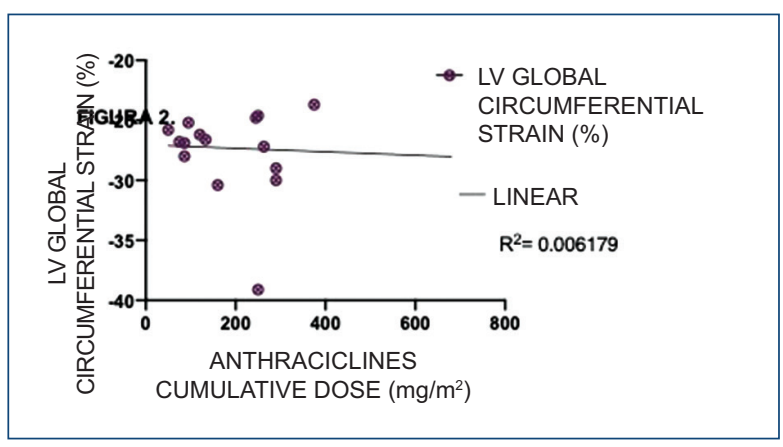

Figure 2. Global circumferential strain versus anthracyclines cumulative dose linear regression.

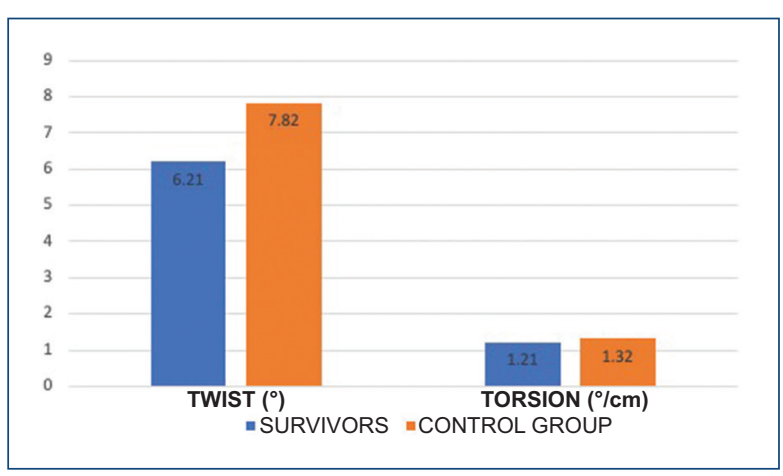

Figure 3. Left ventricular twist and torsion (strain) comparison between survivors and the control group.

can be considered for future studies. The main limitations include the small sample size, the difficulty to match the study cases with the children who participated as controls, and the inability to carry out an intra and inter-observer variability analysis in more study 
parameters. A highly important limitation is that most study patients did not undergo an echocardiographic examination focused on the evaluation of cardiotoxicity with strain before the start of oncological therapy that would enable to early assess the appearance of subclinical cardiac functional or anatomical abnormalities.

\section{Conclusions}

Childhood cancer survivors who were treated with anthracyclines can experience early changes in ventricular myocardial fibers deformation, which reflect in decreased strain, even with normal EF, as well as arrhythmias in those treated with radiation therapy to the mediastinum, as it was observed in the studied patients and which agrees with international publications. Evaluation of these variables is highly important to predict the risk of heart failure, which derives in the need for a protocol-based follow-up to be carried out in exposed patients.

Knowledge of these alterations will enable having better guidance on how to treat these subjects, since on reaching adulthood they will also be exposed to environmental and genetic factors that will make them more prone to suffer from chronic-degenerative diseases, which will require working on secondary and tertiary prevention; moreover, the obtained information can be used to justify the material and human resources to create cardio-oncology clinics and to improve the quality of care in this group of patients.

\section{Acknowledgments}

The authors express their appreciation to the invaluable collaboration of nurse Erika Aguilar, who during the study was assigned to the Pediatric Echocardiography Department, and who supported both the administrative and operational parts in the care of the assessed patients.

\section{Funding}

This research has not received any specific grant from agencies of the public, commercial, or non-profit sectors.

\section{Conflicts of interest}

None.

\section{Ethical disclosures}

Protection of human and animal subjects. The authors declare that no experiments were performed on humans or animals for this research.

Confidentiality of data. The authors declare that they have followed the protocols of their work center on the publication of patient data.

Right to privacy and informed consent. The authors have obtained informed consent from the patients or subjects referred to in the article. This document is in the possession of the corresponding author.

\section{References}

1. Lipshultz SE, Diamond MB, Franco VI, Aggarwal S, Leger K, Santos MV, et al. Managing chemotherapy related cardiotoxicity in survivors of childhood cancers. Paediatric Drugs. 2014;16(5):373-89. doi: 10.1007/ s40272-014-0085-1.

2. Vargas-Neri JL, Castelán-Martínez OD, de Jesús Estrada-Loza M, Betanzos-Cabrera Y, Rivas-Ruiz R. Anthracycline-induced cardiotoxicity: report of fatal cases. Rev Med Inst Mex Seguro Soc. 2016;54(3):404-8.

3. Gallegos CS. Estrategias de cardioprotección en oncohematología pediátrica. GAMO. 2009;8(3):35-9.

4. Lipshultz SE, Colan SD, Gelber RD, Pérez-Atayde AR, Sallan SE, Sanders SP. Late cardiac effects of doxorubicin therapy for acute lymphoblastic leukemia in childhood. N Engl J Med. 1991;324(12):808-15.

5. Kremer LCM, van Dalen EC, Offringa M, Voute PA. Frequency and risk factors of anthracycline-induced clinical heart failure in children: a systematic review. Ann Oncol. 2002;13(4):503-12.

6. Mertens AC, Liu Q, Neglia JP, Wasilewski K, Leisenring W, Armstrong GT, et al. Cause-specific late mortality among 5-year survivors of childhood cancer: the Childhood Cancer Survivor Study. J Natl Cancer Inst. 2008;100(19):1368-79.

7. Tukenova M, Guibout C, Oberlin O, Doyon F, Mousannif A, Haddy N, et al. Role of cancer treatment in long-term overall and cardiovascular mortality after childhood cancer. J Clin Oncol. 2010;28(8):1308-15.

8. López-Fernández T. Cardio-onco-hematologia en la práctica clínica. Documento de consenso y recomendaciones. Rev Esp Cardiol. 2017.

9. Zylberman M, Agüero R. Consenso de diagnóstico, prevención y tratamiento de la cardiotoxicidad por tratamiento médico del cáncer. Rev Argent Cardiol. 2013;81(5):1-64.

10. Albini A, Pennesi G, Donatelli F, Cammarota R, De Flora S, Noonan DM. Cardiotoxicity of anticancer drugs: the need for cardio-oncology and cardio-oncological prevention. J Natl Cancer Inst. 2010;102:14-25.

11. Plana JC, Galderisi M, Barac A, Ewer MS, Ky B, Scherrer-Crosbie M, et al. Expert consensus for multimodality imaging evaluation of adult patients during and after cancer therapy: a report from the American Society of Echocardiography and the European Association of Cardiovascular Imaging. J Am Soc Echocardiogr. 2014;27(9):911-39.

12. Ewer MS, Lippman SM. Type II chemotherapy-related cardiac dysfunction: time to recognize a new entity. J Clin Oncol. 2005;23:2900-2.

13. Velásquez CA, González M, Berrouet MC, Jaramillo N. Cardiotoxicidad inducida por la quimioterapia desde las bases moleculares hasta la perspectiva clínica. Rev Colomb Cardiol. 2016;23(2):104-11.

14. Florescu M, Cinteza M, Vinereanu D. Chemotherapy-induced cardiotoxicity. Mædica. 2013;8(1):59-67.

15. Adão R, de Keulenaer G, Leite-Moreira A, Brás-Silva C. Cardiotoxicidade associada à terapêutica oncológica: mecanismos fisiopatológicos e estratégias de prevencão. Rev Port Cardiol. 2013;32(5):395-409.

16. Lipshultz SE, Sambatakos P, Maguire M, Karnik R, Ross SW, et al. Cardiotoxicity and cardioprotection in childhood cancer. Acta Haematol. 2014;132(3-4):391-9.

17. Diamond $M$, Franco V. Preventing and treating anthracycline-related cardiotoxicity in survivors of childhood cancer. Curr Cancer Ther Rev. 2012;8:141-51.

18. Dillenburg RF, Nathan P, Mertens L. Educational paper: decreasing the burden of cardio- vascular disease in childhood cancer survivors: an update for the pediatrician. Eur J Pediatr. 2013;172:1149-60.

19. Zamorano JL, Lancellotti P, Muñoz DR, Aboyans V, Asteggiano R. 2016 ESC Position Paper on cancer treatments and cardiovascular toxicity developed under the auspices of the ESC Committee for Practice Guidelines. European Heart Journal. 2016;37:2768-801. 
Arch Cardiol Mex (Eng). 2021;91(1)

20. Sawaya H, Plana JC, Scherrer-Crosbie M. Newest echocardiographic techniques for the detection of cardiotoxicity and heart failure during chemotherapy. Heart Fail Clin. 2011;7:313-21.

21. Sawaya $\mathrm{H}$, Sebag IA, Plana JC. Early detection and prediction of cardiotoxicity in chemotherapy-treated patients. Am J Cardiol. 2011;107:1375-80.

22. Çetin S, Babaoğlu K, Başar EZ, Deveci M, Çorapçıŏlu F. Subclinical anthracycline-induced cardiotoxicity in long-term follow-up of asymptomatic childhood cancer survivors: Assessment by speckle tracking echocardiography. Echocardiography. 2018;35:234-40.
23. Pignatelli RH, Ghazi $\mathrm{P}$, Reddy SC, Thompson $\mathrm{P}$, Cui $\mathrm{Q}$. Abnormal myocardial strain indices in children receiving anthracycline chemotherapy. Pediatr Cardiol. 2015;36:1610-6.

24. Yingchoncharoen T, Agarwal S, Popović ZB, Marwick TH. Normal ranges of left ventricular strain: a meta-analysis. J Am Soc Echocardiogr. 2013;26:185-91

25. Venneri L, Zoppellaro G, Khattar RS. Cardio-oncology: the role of advanced echocardiography in cancer patients. Expert Rev Cardiovasc Ther. 2018;16:249-58. 